\title{
Predictor Factors of Atherosclerosis and Atherosclerosis Plaque in Rheumatoid Arthritis Patients
}

\author{
Joko Rilo Pambudi , Harry Isbagio ${ }^{1}$, Rahmad Mulyadi², Murdani Abdullah'
}

${ }^{1}$ Internal Medicine Department ${ }^{2}$ Radiology Department, Faculty of Medicine University of Indonesia, Jakarta Corespondence: Joko Rilo Pambudi, MD E-mail: rilo_pambudi@ yahoo.com

\begin{abstract}
Background: Atherosclerosis and cardiovascular diseases have been known as the cause of increasing mortality among rheumatoid arthritis (RA) patients. Carotid intima media thickness (CIMT) measurement by ultrasound has been used as surrogate marker of atherosclerosis and cardiovascular disease.

Methods: A cross sectional study of 86 RA patients fulfills EULAR/ACR 2010 critera for RA was conducted to study proportion and predictor factors of atherosclerosis and atherosclerosis plaque in rheumatoid arthritis patients.

Results: Atherosclerosis and plaque was found in $47,7 \%$ and $29 \%$ of patients. Age $\geq 40$ yo, hypertension and duration of illness $\geq 24$ mo were associated with atherosclerosis in multivariate logistic regression analysis with OR 10.70 (95\% Cl: 2.93-39.10), 4.99 (95\% Cl: 1.15-21.61) and 3.66 (95\% Cl: 1.11-11.99) respectively. Whereas hypertension, presence of antiCCP antibody and age $\geq 40$ yo, were associated with plaque formation with OR 3.96 (95\% Cl: 1.15-13.57), 3.20 (95\% Cl: 1.11-9.24) and 3.61 (95\% Cl: 1.03-12.63) respectively.
\end{abstract}

Conclusions: Age $\geq 40$ yo, hypertension and duration of illness $\geq 24$ mo was the predictors of atherosclerosis, while hypertension, presence of antiCCP antibody and age $\geq 40$ yo was the predictors of atherosclerosis plaque.

Key words: atherosclerosis, intima media thickness, predictor, rheumatoid arthritis, ultrasonography.

\section{Introduction}

Rheumatoid Arthritis (RA) is a rheumatoid disease marked by the presence of autoimmunity and systemic chronic inflammation. This chronic disease, which occurs in $0.5-1.0 \%$ of population, causes progressive polyarthritis inflammation and joints damage. ${ }^{1}$ Other than the increase in morbidity associated with the joint damage, RA patients are also associated with increased mortality when compared to the normal population. ${ }^{2,3}$ The mechanism by which increase cardiovascular mortality occurs in RA patients is a complex one. The increase in cardiovascular morbidity and mortality in RA patients may not be completely attributed to the traditional risk factors such as obesity, dyslipidemia, diabetes mellitus, hypertension, and smoking., ${ }^{4,5}$ This chronic inflammatory condition in RA causes not only synovitis of the joints, but also causes, and is related to, the development of atherosclerosis and/or atherosclerotic plaques in the vascular system.

The atherosclerosis and cardiovascular diseases are appears to be the primary cause of early death in RA and other autoimmune diseases, as compared to the normal population. Myocardial infarction, ischemic heart disease, heart failure, sudden death, and stroke have become the primary causes for the increasing cardiovascular mortality. ${ }^{4-6}$

As a result, comprehensive assessment and treatment of the traditional and non-traditional cardiovascular risk factors is an important part of the routine management of RA patients. ${ }^{6}$ The proper identification and stratification of RA patients with a high risk and the immediate treatment is an important part in the management of rheumatoid diseases such as RA.

\section{Methods}

This is a cross-sectional research which was performed at Dr. Cipto Mangunkusumo National General Hospital (RSCM) in Jakarta from October 2012 - March 2013. The subject of this research was patients with RA who came for treatment at the Rheumatology clinic at RSCM, Jakarta; fulfilled the inclusion criteria; and did not fulfill the exclusion criteria. The inclusion criteria employed in this study were RA patients with aged minimum 16 years old when the diagnosis was made, fulfilled the RA criteria of EULAR/ACR 2010, and were willing to participate in this study and have signed the informed consent form. The exclusion criteria were subjects who were pregnant or lactating; those who suffered from a malignant disease; has a history of consuming biologic agents; has a history of myocardial infarction, stroke, or peripheral arterial disease.

The collected data included: the length of time since RA diagnosis, patient age, the presence of risk factors such as hypertension, smoking, type 2 diabetes mellitus, obesity, dyslipidemia, serum anti-CCP antibody levels, antioxidized LDL antibody levels, hand and foot radiology examination to assess RA severity (Sharp ve Heijde Score), Carotid USG examination to assess CIMT and atherosclerotic plaque. The analyzed variables were categorized into groups of yes and no, and associated with the presence of atherosclerosis and atherosclerotic plaques. 
Hypertension was defined using the JNC VII ${ }^{7} \mathrm{DM}$ II based on The Indonesian Society of Endocrinology (PERKENI) 2011 criteria for diagnosis; ${ }^{8}$ smoking was based on the CDC definition; ${ }^{9}$ dyslipidemia based on NCEP/ATP III; ${ }^{10}$ obesity was defined as BMI $\geq 25 \mathrm{~kg} / \mathrm{m}^{2} ;{ }^{11}$ serum anti-CCP antibody levels and antioxidized-LDL antibody levels were considered positive if the results were $>25 \mathrm{U} / \mathrm{mL}$ dan $>30 \mathrm{U} / \mathrm{mL}$, respectively.

USG examination was performed by a professional and full trained radiologist to determine the presence of atherosclerosis and atherosclerotic plaques using the standardized method with B-mode Philips ${ }^{\circledR}$ Sonos 5500 USG and a high frequency linear transducer $(>7 \mathrm{MHz})$. Atherosclerosis was defined by CIMT $\geq 1,0$ mmat the common carotid artery, and/or the internal carotid artery, and/or carotid bulb on the left and/or right side. ${ }^{12-15}$ Atherosclerotic plaque was determined by the presence of one of the following during the atherosclerosis examination: abnormal $\operatorname{CIMT}(\geq 1,5 \mathrm{~mm})$, abnormal shape (bulging into the lumen, loss of alignment with the arterial wall), presence of abnormal wall texture (echo brighter that the surrounding border). ${ }^{12-15}$

\section{Results}

In this research, we included 120 RA patients. From the 120 subjects, we have 93 subjects. Three patients were dropped out due to refuse undergone blood test, USG, and other radiological examination. Further, 4 others patients also refused to undergo the USG and radiology examination after undergoing the blood test. Finally, 86 subjects participated in this study, with complete medical history, laboratory examination, carotid USG and radiology. From the 86 subjects who were analyzed, atherosclerosis was found in 41 subjects (47.7\%) and atherosclerotic plaque in 25 subjects (29\%). The subjects comprised of eight males $(9.3 \%)$ and 78 females $(90.7 \%)$. Other subject characteristics can be seen in Table 1. The carotid artery thickness can be seen in Table 2 .

Table 1. Subject Demographics

\begin{tabular}{|c|c|c|c|c|c|}
\hline Variable & $\begin{array}{l}\text { Total No. of } \\
\text { Subjects } \\
N=86\end{array}$ & $\begin{array}{l}\text { Atherosclerosis } \\
\text { No } \\
\mathrm{N}=45\end{array}$ & $\begin{array}{l}\text { Yes } \\
N=41\end{array}$ & $\begin{array}{l}\text { Atherosclero } \\
\text { No } \\
N=61\end{array}$ & $\begin{array}{l}\text { Plaque } \\
\text { Yes } \\
\mathrm{N}=25\end{array}$ \\
\hline \multicolumn{6}{|l|}{ Gender } \\
\hline Male (\%) & $8(9,3)$ & $4(4,65)$ & $4(4,65)$ & $4(4,6)$ & $4(4,6)$ \\
\hline Female (\%) & $78(90,7)$ & $41(47,67)$ & $37(43,0)$ & $57(66,3)$ & $21(24,4)$ \\
\hline Age (years) ${ }^{*}$ & $49,5(20-70)$ & $38(20-61)$ & $56(28-70)$ & $43(20-70)$ & $56(28-69)$ \\
\hline Duration of disease (months) ${ }^{*}$ & $25,5(2-233)$ & $17(2-133)$ & $36(3-233)$ & $23(2-145)$ & $28(3-233)$ \\
\hline \multicolumn{6}{|l|}{ Treatment (\%) } \\
\hline Methyl prednisolon & $63(73,3)$ & & & & \\
\hline MTX & $54(62,8)$ & & & & \\
\hline SSZ & $17(19,8)$ & & & & \\
\hline $\mathrm{MTX}+\mathrm{SSZ}$ & $15(17,4)$ & & & & \\
\hline \multicolumn{6}{|l|}{ Dosage $^{*}$} \\
\hline Methyl pred(mg/day) & $4(0-16)$ & $4(0-16)$ & $4(0-16)$ & $4(2-16)$ & $4(2-16)$ \\
\hline MTX (mg/week) & 11,25 (SD 3,4) & $10(7,5-17,5)$ & $10(7,5-20)$ & $10(7,5-20)$ & $12,5(7,5-20)$ \\
\hline SSZ (g/day) & $1(1-2)$ & $1(1-2)$ & $1(1-2)$ & 1,28 (SD 0,45) & 1,11 (SD 0,33) \\
\hline DAS 28 Score $^{*}$ & $3,7(2,09-6,47)$ & $3,62(2,09-6,03)$ & $3,70(2,58-6,47)$ & $3,7(2,09-6,03)$ & $3,5(2,70-6,47)$ \\
\hline Remission $(<2,6)$ & $5(5,8)$ & & & & \\
\hline Mild $(\leq 3,2)$ & $17(19,8)$ & & & & \\
\hline Moderate $(>3,2 \leq 5,1)$ & $56(65,1)$ & & & & \\
\hline Severe $(>5,1)$ & $8(9,3)$ & & & & \\
\hline BMI (kg/m²) & 23,9 (SD 4,41) & 23,68 (SD 4,66) & 24,05 (SD 4,18) & 23,7 (SD 4,53) & 24,30 (SD 4,17) \\
\hline $\mathrm{ESR}(\mathrm{mm} / 1 \text { hour })^{*}$ & $45(5-135)$ & $48(5-135)$ & $40(10-110)$ & $49(10-135)$ & $33(5-99)$ \\
\hline \multicolumn{6}{|l|}{ CRP (\%) } \\
\hline Negative & $41(47,7)$ & $20(44,4)$ & $21(51,2)$ & $28(45,9)$ & $13(52,0)$ \\
\hline Positive & $45(52,3)$ & $25(55,6)$ & $20(48,8)$ & $33(54,1)$ & $12(48,0)$ \\
\hline \multicolumn{6}{|l|}{ Rheumatoid Factor (\%) } \\
\hline Negative & $31(36,0)$ & $18(0,4)$ & $13(31,7)$ & $22(36,1)$ & $9(36,0)$ \\
\hline Positive & $55(64,0)$ & $27(0,6)$ & $28(68,3)$ & $39(63,9)$ & $16(64,0)$ \\
\hline \multicolumn{6}{|l|}{ Anti-CCP Antibody (\%) } \\
\hline Negative & $53(61,6)$ & $28(62,2)$ & $25(61,0)$ & $41(67,2)$ & $12(48,0)$ \\
\hline Positive & $33(38,4)$ & $17(37,8)$ & $16(39,0)$ & $20(32,8)$ & $13(52,0)$ \\
\hline \multicolumn{6}{|l|}{ Anti ox-LDL (\%) } \\
\hline Negative & $22(25,6)$ & $10(22,2)$ & $12(29,3)$ & $14(23,7)$ & $8(32,0)$ \\
\hline Positive & $62(72,1)$ & $33(71,1)$ & $29(70,7)$ & $45(76,3)$ & $17(68,0)$ \\
\hline \multicolumn{6}{|l|}{ Hypertension (\%) } \\
\hline No & $70(81,4)$ & $41(91,1)$ & $29(33,72)$ & $53(86,9)$ & $17(68,0)$ \\
\hline Yes & $16(18,6)$ & $4(8,9)$ & $12(13,95)$ & $8(13,1)$ & $8(32,0)$ \\
\hline \multicolumn{6}{|l|}{ Type 2DM (\%) } \\
\hline No & $82(95,35)$ & $45(100)$ & $37(90,2)$ & $60(98,4)$ & $22(88,0)$ \\
\hline Yes & $4(4,65)$ & $0(0,0)$ & $4(9,8)$ & $1(1,6)$ & $3(12,0)$ \\
\hline \multicolumn{6}{|l|}{ Dyslipidemia (\%) } \\
\hline No & $58(67,4)$ & $32(71,1)$ & $26(63,4)$ & $42(68,9)$ & $16(64,0)$ \\
\hline
\end{tabular}




\begin{tabular}{|c|c|c|c|c|c|}
\hline $\begin{array}{c}\text { Yes } \\
\text { Smoking (\%) }\end{array}$ & $28(32,6)$ & $13(28,9)$ & $15(36,6)$ & $19(31,1)$ & $9(36,0)$ \\
\hline No & $85(98,8)$ & $45(100)$ & $40(97,6)$ & $61(100)$ & $24(96,0)$ \\
\hline Yes & $1(1,2)$ & $0(0,0)$ & $1(2,4)$ & $0(0,0)$ & $1(4,0)$ \\
\hline \multicolumn{6}{|l|}{ Obesity (\%) } \\
\hline No & $49(57,0)$ & $27(0,6)$ & $22(53,7)$ & $37(60,7)$ & $12(48,0)$ \\
\hline Yes & $37(43,0)$ & $18(0,4)$ & $19(46,3)$ & $24(39,3)$ & $13(52,0)$ \\
\hline \multicolumn{6}{|c|}{ Sharp van Heijde Score* } \\
\hline Total & $32(0-355)$ & $28(0-355)$ & $40(2-121)$ & $31(0-355)$ & $40(2-107)$ \\
\hline Hand & $20(0-271)$ & $17(0-271)$ & $23(1-97)$ & $19(0-271)$ & $23(1-95)$ \\
\hline Foot & $10(0-84)$ & $9(0-84)$ & $11(0-24)$ & $9(0-84)$ & $11(0-21)$ \\
\hline
\end{tabular}

* Median (minimum-maximum), SD: Standard Devia tion

Table 2. Carotid Artery CIMT

\begin{tabular}{cl}
\hline Artery & CIMT (min-max) mm \\
\hline Common Carotid Artery & $0,683(0,39-1,94)$ \\
Internal Carotid Artery & $0,705(0,45-2,04)$ \\
Carotid Bulb & $0,850(0,38-4,34)$ \\
\hline
\end{tabular}

Bivariate analysis showed that the predicting factors associated with the presence of atherosclerosis in RA were patients aged $\geq 40$ years, duration of illness $\geq 24$ months, hypertension and type 2DM. The predicting factors associated with the presence of atherosclerotic plaque in RA patients were age $\geq 40$ years; duration of illness $\geq 24$ months; hypertension;type 2DM; and the anti CCP antibody status. Smoking was not included in the bivariate analysis or the multivariate analysis because only 1 subject was a smoker.

Variables in the bivariate analysis with $\mathrm{p}$ value $<0.25$ were age $\geq 40$ years, illness duration $\geq 24$ months, hypertension, and type $2 \mathrm{DM}$ were included in the multivariate analysis for atherosclerosis. The variables age $\geq 40$ years, illness duration $\geq 24$ months, hypertension, type $2 \mathrm{DM}$, and the anti CCP antibody status were included in the multivariate analysis for atherosclerotic plaques. The multivariate analysis of the variables can be seen in Table 3 and 4 .

Table 3. Atherosclerosis Multivariate Analysis

\begin{tabular}{lll}
\hline Variable & $\mathbf{O R}(\mathbf{9 5} \% \mathbf{C l})$ & $\mathbf{p}$ \\
\hline Age $>$ 40 years & $10,70(2,93-39,10)$ & $<0,001$ \\
$\begin{array}{l}\text { Hypertension } \\
\begin{array}{l}\text { Duration of illness } \geq 24 \\
\text { months }\end{array}\end{array}$ & $4,99(1,15-21,61)$ & 0,031 \\
\hline
\end{tabular}

Table 4. Atherosclerotic Plaque Multivariate Analysis

\begin{tabular}{lll}
\hline Variable & $\mathbf{O R}(\mathbf{9 5} \% \mathbf{c l})$ & $\mathbf{p}$ \\
\hline Hypertension & $3,96(1,15-13,57)$ & 0,029 \\
Anti CCP Antibody & $3,20(1,11-9,24)$ & 0,031 \\
Age $\geq 40$ years & $3,61(1,03-12,63)$ & 0,044 \\
\hline
\end{tabular}

Multivariate analysis revealed that the variables with statistical significance for the occurrence of atherosclerosis, in order, were age $\geq 40$ years, hypertension, and illness duration $\geq 24$ months; whereas for atherosclerotic plaque, in order, were hypertension, Anti CCP antibody status, and age $\geq 40$ years.

To predict the probability of atherosclerosis and atherosclerotic plaque, multivariate analysis provided the regression coefficient for each variable. Based on the analysis, the probability for atherosclerosis and atherosclerotic plaques were each calculated using the specific model equation based on the presence of specific variables in the individual.

The probability model equation obtained was:

For atherosclerosis, the equation for probability was $=\mathrm{P}=1$ / $1+\mathrm{e}^{-\mathrm{y}}$

$\mathrm{e}=$ constant, 2.7

$\mathrm{y}=$ the equation obtained from multivariate analysis using logistic regression, for atherosclerosis $\mathrm{y}=-(-3,068+2,370$ [age $\geq 40$ years] $+1,296$ [duration of illness $\geq 24$ months] + 1,608 [hypertension]),

Therefore $\mathrm{P}=$ 1

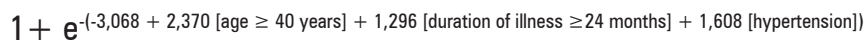

For atherosclerotic plaque, the probability $=$

1

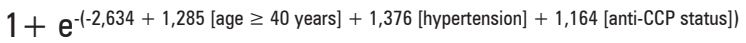

To simplify and allow easy use of the probability prediction for atherosclerosis and atherosclerotic plaque in daily practice, thus a scoring system was constructed. The use of this scoring system allows easier identification and stratification of RA patients with a high cardiovascular risk.

The prediction score for atherosclerosis and atherosclerotic plaque for each variable was made based on the rounding of the result from the division of the regression coefficient with the standard error (SE) from each predicting variable. Thus, the score for each variable (Table 5 and 6 ), are obtained.

Table 5. Atherosclerosis Prediction Score

\begin{tabular}{llllll}
\hline Variable & B & SE & B/SE & Score & Rounded To \\
\hline Age $\geq 40$ years & 2,370 & 0,661 & 3,585 & 1,67 & 2 \\
Duration of illness $\geq 24$ months & 1,296 & 0,606 & 2,139 & 1,00 & 1 \\
Hypertension & 1,608 & 0,747 & 2,152 & 1,01 & 1 \\
\hline
\end{tabular}

Table 6. Atherosclerotic Plaque Prediction Score

\begin{tabular}{llllll}
\hline Variable & B & SE & B/SE & Score & Rounded To \\
\hline Age $\geq 40$ years & 1,285 & 0,638 & 2,014 & 1,00 & 1 \\
Anti-CCP Status & 1,164 & 0,541 & 2,152 & 1,07 & 1 \\
Hypertension & 1,376 & 0,629 & 2,186 & 1,09 & 1 \\
\hline
\end{tabular}


Based on the available score for each variable, with the logistic regression, a total score can be obtained, thus allowing measurement of the probability for atherosclerosis and atherosclerotic plaque based on the total score for every individual.

For atherosclerosis, the probability, based on the total score, can be calculation using the following equation:

$$
\frac{1}{1+\mathrm{e}^{-(-3,077+1,248 \text { [total score] })}}
$$

From this equation, the probability for each total score can be calculated (Table 7).

Table 7. The Probability of Atherosclerosis Based on the Total Score

\begin{tabular}{cc}
\hline Total Score & Probability of Atherosclerosis \\
\hline 0 & $4,5 \%$ \\
1 & $14 \%$ \\
2 & $36 \%$ \\
3 & $66 \%$ \\
4 & $76 \%$ \\
\hline
\end{tabular}

For atherosclerotic plaque, the probability can be calculated based on the total score by the following equation:

$$
1
$$

$$
1+\mathrm{e}^{-(-2,638+1,265[\text { total score }])}
$$

From this equation the probability for each score can be calculated (Table 8).

Table 8. Probability of Atherosclerotic Plaque Based on the Total Score

\begin{tabular}{cc}
\hline Total Score & Probability of Atherosclerotic Plaque \\
\hline 0 & $7 \%$ \\
1 & $20 \%$ \\
2 & $47 \%$ \\
3 & $76 \%$ \\
\hline
\end{tabular}

The prediction score for atherosclerosis and atherosclerotic plaque have been tested for the quality or performance by calibration test (Hosmer-Lemeshow Test) and for discrimination ability by observing the result of the under receiver operating characteristic curve[AUC].In the atherosclerotic prediction score the Hosmer Lemeshow got a result of $p=0.794(p>0.05)$ which indicates that the precision is good. Similarly, the discrimination ability to differentiate patients who will suffer atherosclerosis from those who will not have atherosclerosis was also good (AUC $=0.800 ; 95 \%$ CI 0.707 - 0.892).For the prediction of atherosclerotic plaque occurrence, the Hosmer Lemeshow score $p=0.696(p>0.05)$ which indicates that the prediction model has good precision. The discrimination ability of the atherosclerotic plaque prediction score based on the AUC is moderate $(\mathrm{AUC}=0.719$; 95\% CI 0.599-0.839).

The second internal validation of the scoring system was done using the Bootstrapping method. Following validation, the Hosmer Lemeshow test gave a p value of 0.838 and 0.956 for atherosclerosis and atherosclerotic plaque, respectively. The Hosmer-Lameshow $p$ value $>0.05$ after the Bootstrapping method was done to show that the two prediction scores were internally validated ina proper manner.

\section{Discussion}

This research involved 86 subjects, eight (9.3\%) males and 78 females $(90.7 \%)$. However, this observation varies from previous research which show that the proportion of males to females is $3: 4$. This may be caused by the difference in the population, location of research, and inclusion and exclusion criteria. Further, the median age of subjects in this research is 49.5 years. The youngest subject being 20 years old and the oldest 70 yeasr old. Similar results are reported in other studies which show that RA is most commonly found in the $4^{\text {th }}-5^{\text {th }}$ decades. Furthermore, the duration of illness in the subjects of this study ranged from 2 months till 9.7 years.

Disease activity, as assessed by the DAS-28LED Score, was moderate in majority of the patients (65\%). High disease activity was found in $9 \%$ of the subjects, low activity in $20 \%$ of the subjects, and only $6 \%$ were in remission. The small proportion of patients in remission and a low average weekly MTX dose $(11.25 \mathrm{mg})$, and the limited types of DMARDs available appear to be correlated. This may be attributed to the limited DMARD options available at the medical formularium and the lack of funds among the patients. Moreover, this small percentage of patients in remission necessitates additional consideration and further research.

Atherosclerosis (CIMT $\geq 1.0 \mathrm{~mm}$ ) and atherosclerotic plaque were found in 41 subjects $(47.7 \%)$ and 25 subjects (29\%), respectively. The cut-off for CIMT of $\geq 1.0 \mathrm{~mm}$ was used in this study is considered to increase the risk for a cardiovascular event in the future. This cut-off is also the level used by the Radiology Department at FKUI/RSCM Jakarta where USG examination and other research are conducted. ${ }^{12,14,15}$

The proportion of subjects with atherosclerosis and atherosclerotic plaques were different compared to previous studies. This may be attributed to the difference in definition, cut-off values, population, examination methods, location, and measuring instruments used. Different academic centers and research groups have different cut-off values, methods and examination approaches. ${ }^{16}$

Gender was not identified as a significant risk factors with the occurrence of atherosclerosis by bivariate and multivariate analysis. In this study, there were only eight male subjects $(9.3 \%)$ with a proportion of $1: 10$ compared to the number of female subjects, lower than the proportions mentioned in the literature. Currently, no research has ever reported the association of a specific gender with the occurrence of atherosclerosis in RA patients.

In this research, age $\geq 40$ years and duration of illness $\geq$ 24 months are significantly associated with the occurrence of atherosclerosis. Through logistic regression analysis on atherosclerosis, the OR for age $\geq 40$ years and duration of illness $\geq 24$ months were 10.7 (CI 95\% 2.93 - 39.1; $<<0.001$ ) and 3.66 (CI 95\% $1.11-11.99 ; \mathrm{p}=0.032)$, respectively. In the analysis for atherosclerotic plaque, a significant association 
was found with age $\geq 40$ years, the OR being 3.61 (CI 95\% $1.03-12.63 ; p=0.044)$.

Age and duration of illness were associated with CIMT in this research, similar to the findings in other studies. ${ }^{17-21}$ Atherosclerosis is a chronic, continuous process which begins at a young age and grows with age. CIMT in the healthy population usually increase with age. ${ }^{22}$ Age is a primary factor that determines the extent of atherosclerosis. Longer an individual suffers from RA, more severe is the atherosclerosis compared to patients of the same age but earlier in the course of the disease. This finding is similar to that reported by Rincon et al. ${ }^{23}$

Hypertension is a traditional predicting factor, significantly associated with atherosclerosis and atherosclerotic plaque formation, OR 4.99 (CI 95\% $1.15-21.16 ; \mathrm{p}=0.031$ ) and 3.96 (CI 95\% $1.15-13.57 ; \mathrm{p}=0.029)$, respectively. However a significant association between hypertension and CIMT was not found in the study by Gonzales-Juanatey. ${ }^{20}$ On the other hand, Roman MJ showed that in RA patients, atherosclerosis is associated with age, hypertension status, and use of TNF alpha inhibitors. ${ }^{19}$ In this study, hypertension was a significant risk factor for atherosclerosis and atherosclerotic plaque formation that can be changed and treated.

Type 2 Diabetes Mellitus was not a predicting factor for the occurrence of atherosclerosis and atherosclerotic plaques in this research. Similarly, MJ Roman, YB Park, and Ahmed also reported the same results. ${ }^{17,19,21}$ Different population, genetics, background, RA diagnostic criteria, and also atherosclerosis and atherosclerosis plaque diagnostic critera may cause discrepancy between our result and the others study result.

Dyslipidemia isn't a predicting factor of atherosclerosis and atherosclerosis plaque in this study. Similarly with YB Park and MJ Roman study. ${ }^{17,19}$ A complex relationship between dyslipidemia, inflammation, and RA may be the reason underlying the lack of a significant association between dyslipidemia and atherosclerosis in this research, other than the difference in population, RA diagnostic criteria, and method of atherosclerosis examination.

Smoking is a traditional predicting factor for the occurrence of atherosclerosis. In addition, it causes more severe joint damage in RA. However, in this research smoking was not significantly associated with atherosclerosis. There is a need for more subjects who have a smoking habit to correctly identify the role of smoking as the predicting factor for atherosclerosis and atherosclerotic plaques. The study by MJ Roman also reported smoking as a significant predicting factor for atherosclerotic plaques. ${ }^{19}$

The median BMI in this research was $23.9 \mathrm{~kg} / \mathrm{m}^{2}$ (SE 4.4). Obesity (BMI $\geq 25 \mathrm{~kg} / \mathrm{m}^{2}$ ) was not significantly associated with the occurrence of atherosclerosis in this research. This finding is in accordance with the study by Kremer et al. ${ }^{24}$ Different from the common population, RA patients with low BMI $\left(<20 \mathrm{~kg} / \mathrm{m}^{2}\right)$ had a higher risk for cardiovascular death compared to non-RA patients with normal BMI. Moreover, in RA, BMI has a paradoxical effect on mortality. Patients with $\mathrm{BMI} \geq 30$ had lower mortality rate $(1.7$ deaths / 100 individuals/year) compared to patients with BMI $<20(10.5$ deaths/ 100 individuals/year) ${ }^{25}$ More severe the inflammation appears to be correlated with more severe cachexia that is correlated with increase morbidity rate.

Anti-CCP antibodies were found in 33 subjects (38.4\%) in this study. The presence of anti-CCP antibodies was not significantly correlated with the occurrence of atherosclerosis, but the association with atherosclerotic plaque was significant, with OR 3.2 (CI 95\% $1.1-9.2 ; \mathrm{p}=0.029$ ). The significant association between anti-CCP with atherosclerotic plaque formation was also reported by Lopez FJL, et al where RA patients with positive anti-CCP antibodies $(>25$ unit $/ \mathrm{mL})$ had higher myocardial ischemia (6.5\% vs. $2.6 \%$; OR 2.56 , CI $95 \% 1.17-5.56)$ and mortality rates ( $11.2 \%$ vs. $6.8 \%$; OR 1.72 , CI 95\% 1.01 - 2.91) compared to RA patients without anti-CCP antibodies. They demonstrated an association between anti-CCP antibodies of patients with RA and the presence of coronary heart disease independent of traditional cardiovascular risk factors. Their report revealed an underlying autoimmune inflammatory disorder affecting not only the development of articular RA manifestations, but also the cardiovascular comorbidity of RA. ${ }^{26}$

Another research in the Rheumatology Clinic at RSCM by Yuliani and Manuaba reported the prevalence of anti-CCP antibodies at $60.4 \%$ (91 subjects) and 56\% (46 subjects), respectively. ${ }^{27,28}$ This difference may be attributed to the difference in population, RA diagnostic criteria, and method of examination.

The prevalence of antioxidized-LDL antibodies in this research was $61.6 \%$ (53 out of 86 subjects). A significant association between anti oxidized-LDL antibodies with atherosclerosis or atherosclerotic plaque formation was not found. In contrast, Ahmed et al, reported that patient age, CRP, and Ox-LDL antibodies were independent risk factors of atherosclerosis. ${ }^{21}$ This difference may be caused by the variation in atherosclerosis and atherosclerotic plaque criteria and definition, as well as the method of examination.

Radiology examination score in a cross sectional research describes the severity of joint damage occurring in RA at a specific point of time. In this research, a median Sharp van Heidje score of 28 and 40 for patients with and without atherosclerosis, respectively; and 31 and 40 for patients with and without atherosclerotic plaques, respectively. The differences were not statistically significant. The complex interaction between inflammation, joint damage, and occurrence of atherosclerosis may underlie this result. Similarly, Gonzales-Juanatey et al, did not find a significant association between joint damage (using the Larsen score) with carotid CIMT and carotid plaques. ${ }^{29}$

Multivariate analysis by logistic regression testing allowed the construction of a scoring system which calculates the probability of atherosclerosis and atherosclerotic plaque formation for each score. The prediction score of $0,1,2,3$, and 4 are associated with a $4 \%, 14 \%, 36 \%$, and $87 \%$ probability of developing atherosclerosis, respectively. On the other hand, the score $0,1,2$, and 3 are associated with a $7 \%, 20 \%, 47 \%$, and $76 \%$ probability of developing an atherosclerotic plaque, respectively.

Based on the prediction scores for atherosclerosis and atherosclerotic plaque formation, the researchers categorized 
the prediction scores into low, moderate, and high. For the atherosclerosis prediction score $0-$ is low risk with a probability of up to $14 \%$ for the occurrence of atherosclerosis $(\mathrm{CIMT} \geq 1.0 \mathrm{~mm})$. A score of 2 with a $36 \%$ probability of developing atherosclerosis is categorized as moderate risk. Further, a score of $3-4$ are categorized as high risk, with a $66 \%$ to $97 \%$ risk of developing atherosclerosis. For patients with moderate risk, the researchers recommend CIMT examination to determine the presence of thickening of the tunica intima. For high risk patients, primary prevention of atherosclerosis complications and cardiovascular events, without CIMT examination is recommended (Table 11).

Similarly, there is the prediction scores for the development of atherosclerotic plaques. A score of 0 is considered as low risk with a $7 \%$ probability of atherosclerotic plaque. A score of 1 with a $20 \%$ probability of atherosclerotic plaque formation is considered as moderate risk, and the researchers suggest CIMT measurement for these patients. Further, a score of 2 -3 is considered as high risk with at least a $47 \%$ probability of developing atherosclerotic plaques. In patients with high risk, primary prevention is recommended without the need for CIMT examination (Table 12).

Table 9. Recommendations Based on Atherosclerosis Prediction Scores

\begin{tabular}{llll}
\hline Score & Risk & $\begin{array}{l}\text { Probability of } \\
\text { Atherosclerosis }\end{array}$ & Recommendation \\
\hline $0-1$ & Low & $14 \%$ & Observation \\
2 & Moderate & $36 \%$ & CIMT Examination \\
$3-4$ & High & $66-87 \%$ & Primary Prevention \\
\hline
\end{tabular}

Table 10. Recommendations Based on Atherosclerotic Plaque Prediction Scores

\begin{tabular}{llll}
\hline Score & Risk & $\begin{array}{l}\text { Probability of } \\
\text { Atherosclerotic } \\
\text { Plaques }\end{array}$ & Recommendation \\
\hline 0 & Low & $7 \%$ & Observation \\
1 & Moderate & $20 \%$ & CIMT Examination \\
$2-3$ & High & $47-76 \%$ & Primary Prevention \\
\hline
\end{tabular}

Internal validation of this predictive study was conducted using the Bootstrapping method in the statistical software, SPSS. Following 1000 times of sample repetition, the HosmerLameshow value for atherosclerosis and atherosclerotic plaque formation were 0.838 and 0.956 , respectively. Both of the $p$ values were $>0.05$, thus it may be assumed that the internal validation of this research is good, for the prediction factors of atherosclerosis and atherosclerotic plaque formation.

For external validation, a multicenter research must be conducted with a similar design on the RA population in a different location. The aim of performing a multicenter study is to identify the inference and generalization ability of this study to RA patients in Indonesia, thus allowing the construction of more definite suggestions and recommendations.

Currently, to the researchers' knowledge, this is the first study which focuses on identifying the relationship between the predicting factors, including the demographic (age and duration of illness), clinical (presence of hypertension, diabetes mellitus, dyslipidemia, and obesity), laboratory (presence of anti-CCP and antioxidized-LDL antibodies), and radiology variables (Sharp van Heijde Score) with the occurrence of atherosclerosis and atherosclerotic plaques, identified by CIMT examination as the surrogate marker, by multivariate analysis among the RA population in Indonesia. The results of this research, obtained by multivariate analysis, may be used as the background for more developed research to determine the relationship or association between the independent and dependent variables (atherosclerosis and atherosclerotic plaques), using this research design which is more simple and focused. It is recommended for further research to examine and further identify the role of those significant factors, and to focus on the relationship between hypertension and anti-CCP antibodies with atherosclerosis and atherosclerotic plaque formation.

The results of this study hints on the possible role that anti-CCP antibodies, an important and relatively novel serology analysis in Indonesia, may play in the formation of atherosclerosis and atherosclerotic plaque formation. The significant association between the presence of anti-CCP antibodies and atherosclerotic plaque formation indicates the role of autoimmunity in RA, atherosclerosis, and atherosclerotic plaque formation. The results of this research serve as evidence to the role anti-CCP antibodies in the development of subclinical atherosclerosis and ischemic heart disease in RA patients. ${ }^{26,29}$

For clinicians who deal with RA patients on a regular basis, the results of this research provides a screening and stratification tool for RA patients and their probability of developing atherosclerosis and atherosclerotic plaques.

The cross sectional design of this study does not allow a cause-and-effect analysis of the predicting variables and the outcomes, atherosclerosis and atherosclerotic plaques. Further research with a cohort design is required to clarify the cause and effect relationship between the predicting variables with atherosclerosis and atherosclerotic plaques.

Smoking was not analyzed as a variable because only 1 patient was a smoker. However, smoking has been proven and is known to be an important predicting factor of atherosclerosis and atherosclerotic plaque formation in the non-RA population. The role of smoking as a predicting factor could not be analyzed in this study, thus smoking should be considered in the generalization and inference of the results obtained in this study. The researchers recommend clinical judgment, still more important than the scoring system constructed from this research.

Predicting model or scoring system obtained from this research does not analyze the duration of hypertension, diabetes mellitus, or quantity/length of time of smoking history. This research did not consider the therapy or drugs/ combination of DMARDs or other medications such as anti-hypertensives or statins being consumed or have been consumed, which may affect the occurrence of atherosclerosis and/or atherosclerotic plaques. Ultrasound and radiology examinations for atherosclerosis plaque and Sharps van Heidje score was done by one examiner respectively for all subjects. 


\section{Conclusion}

The proportion of atherosclerosis and atherosclerotic plaques among RA patients was $47.7 \%$ and $29 \%$, respectively. Age $\geq$ 40 years, hypertension, and duration of illness $\geq 24$ months are, in order, significant predicting factors for the development of atherosclerosis in RA patients. Hypertension, Anti-CCP status, and age $\geq 40$ years are, in order, the predicting factors for the development of atherosclerotic plaques in RA patients. Regarding this research, there are several recommendations for researchers, clinicians, and policy makers. First, further research is required, using a prospective multicenter design with more detailed categorization (age; duration of illness; length of time since hypertension and diabetes mellitus diagnosis; quantity and types of medications being consumed, etc) for the external validation and to clarify the relationship between the predicting factors and the occurrence atherosclerosis and atherosclerotic plaques among RA patients in Indonesia. For clinicians and other medical professionals who work with RA patients, and the patient's family members should consider patient age, hypertension, duration of RA disease, and antiCCP status in the management of RA to reduce mortality due to cardiovascular events. For policy makers such hospital directors, health ministers, and professional organizations such as Indonesian Doctors Association and The Indonesian Society of Internal Medicine to consider factors such as patient age, hypertension, duration of RA disease, and anti-CCP status when constructing the standard operating procedures, clinical practice guidelines, or medical treatment guidelines for the management of RA, to increase the quality of patient treatment; and to allow the optimal, appropriate, and costeffective use of resources.

\section{References}

1. Sattar N, McInnes IB. Atherosclerosis in rheumatoid arthritis. In: Firestein GS, Budd RC, Jr. EDH, editors. Kellys'Textbook of Rheumatology. 8 ed. Philadelphia: Saunders Elsevier; 2008.

2. Gabriel SE, Crowson CS, Kremers HM, Doran MF, Turesson C, O'Fallon WM, et al. Survival in rheumatoid arthritis: a population-based analysis of trends over 40 years. Arthritis \& Rheumatism. 2003;48(1):54-58.

3. van Doornum S, McColl G, Wicks IP. Accelerated atherosclerosis: an extraarticular feature of rheumatoid arthritis? Arthritis \& Rheumatism. 2002;46(4):862-873.

4. Solomon DH, Karlson EW, Rimm EB, al. e. Cardiovascular morbidity and mortality in women diagnosed with rheumatoid arthritis. Circulation. 2003;107:1303-1307.

5. del Rincon ID, Williams K, Stern MP, Freeman GL, Escalante A. High incidence of cardiovascular events in a rheumatoid arthritis cohort not explained by traditional cardiac risk factors. Arthritis \& Rheumatism. 2001;44(12): 2737-2345.

6. Dessein $\mathrm{PH}$, Joffe $\mathrm{BI}$. When is a patient with rheumatoid arthritis at risk for cardiovascular disease? J Rheumatol. 2006;33:201-203.

7. Chobanian AV, Bakris GL, Black HR, Cushman WC, Green LA, Izzo $\mathrm{JL}$, Jr., et al. Seventh report of the Joint National Committee on prevention, detection, evaluation, and treatment of high blood pressure. Hypertension. 2003;42(6):1206-1252.

8. PERKENI. Konsensus pengelolaan dan pencegahan diabetes melitus tipe 2 di Indonesia 2011. Jakarta: Pusat Penerbitan IImu Penyakit Dalam FKUl; 2011.
9. Centers for Disease CP. State-specific second hand smoke exposure and current cigarette smoking among adults - United States, 2008. MMWR Morbidity and mortality weekly report. 2009;58(44):1232-1235.

10. Program NCE. Detection, evaluation, and treatment of high blood cholesterol in adults (adult treatment panel III). National Institutes of Health; 2002.

11. Region WWP. The Asia-Pacific perspective: redefining obesity and its treatment. Health Communications Australia Pty Limited; 2000.

12. Nambi V, Chambless L, Folsom AR, He M, Hu Y, Mosley T, et al. Carotid intima-media thickness and presence or absence of plaque improves prediction of coronary heart disease risk: the ARIC (Atherosclerosis Risk In Communities) study. Journal of the American College of Cardiology. 2010;55(15):1600-1607.

13. Touboul PJ, Hennerici MG, Meairs S, Adams H, Amarenco P, Bornstein N, et al. Mannheim carotid intima-media thickness and plaque consensus (2004-2006-2011). An update on behalf of the advisory board of the $3 r d, 4$ th and 5th watching the risk symposia, at the 13th, 15th and 20th European Stroke Conferences, Mannheim, Germany, 2004, Brussels, Belgium, 2006, and Hamburg, Germany, 2011. Cerebrovascular diseases. 2012;34(4):290-6.

14. Ravindran V, Rachapalli S. An overview of commonly used radiographic scoring methods in rheumatoid arthritis clinical trials. Clinical rheumatology. 2011;30(1):1-6.

15. Chambless LE, Heiss G, Folsom AR, Rosamond W, Szklo M, Sharrett $A R$, et al. Association of coronary heart disease incidence with carotid arterial wall thickness and major risk factors: the atherosclerosis risk in communities (ARIC) study, 1987-1993. Am J Epidemiol 1997;146(6):48394.

16. Nair SB, Malik R, Khattar RS. Carotid intima-media thickness: ultrasound measurement, prognostic value and role in clinical practice. Postgraduate medical journal. 2012;88(1046):694-9.

17. Park YB, Ahn CW, Choi HK, Lee SH, In BH, Lee HC, et al. Atherosclerosis in rheumatoid arthritis: morphologic evidence obtained by carotid ultrasound. Arthritis \& Rheumatism. 2002;46(7):1714-9.

18. Kumeda $Y$, Inaba $M$, Goto $H$, Nagata $M$, Henmi $Y$, Furumitsu $Y$, et al. Increased thickness of the arterial intima-media detected by ultrasonography in patients with rheumatoid arthritis. Arthritis \& Rheumatism. 2002;46(6):1489-97.

19. Roman MJ, Moeller E, Davis A, Paget SA, Crow MK, Lockshin MD, et al. Preclinical carotid atherosclerosis in patients with rheumatoid arthritis. Annals of Internal Medicine. 2006;144(4):249-56.

20. Gonzalez-Juanatey C, Llorca J, Testa A, Revuelta J, Garcia-Porrua C, Gonzalez-Gay MA. Increased prevalence of severe subclinical atherosclerotic findings in long-term treated rheumatoid arthritis patients without clinically evident atherosclerotic disease. Medicine. 2003;82(6):407-13

21. Ahmed HMMS, Youssef M, Mosaad YM. Antibodies against oxidized low-density lipoprotein are associated with subclinical atherosclerosis in recent-onset rheumatoid arthritis. Clinical rheumatology. 2010;29(11):1237-43.

22. Lim TK, Lim E, Dwivedi G, Kooner J, Senior R. Normal value of carotid intima-media thickness--a surrogate marker of atherosclerosis: quantitative assessment by B-mode carotid ultrasound. Journal of the American Society of Echocardiography : official publication of the American Society of Echocardiography. 2008;21(2):112-6.

23. del Rincon I, O'Leary DH, Freeman GL, Escalante A. Acceleration of atherosclerosis during the course of rheumatoid arthritis. Atherosclerosis. 2007; 195(2):354-60.

24. Maradit-Kremers H, Nicola PJ, Crowson CS, Ballman KV, Gabriel SE. Prognostic importance of low body mass index in relation to cardiovascular mortality in rheumatoid arthritis. Arthritis \& Rheumatism. 2004;50(11):3450-7. 
25. Escalante A, Haas RW, del Rincón I. Paradoxical effect of body mass index on survival in rheumatoid arthritis. Arch Intern Med. 2005;165:6.

26. Lopez-Longo FJ, Oliver-Minarro D, de la Torre I, Gonzalez-Diaz de Rabago E, Sanchez-Ramon S, Rodriguez-Mahou M, et al. Association between anti-cyclic citrullinated peptide antibodies and ischemic heart disease in patients with rheumatoid arthritis. Arthritis and rheumatism. 2009;61 (4):419-24.

27. Yuliani IW. Prevalensi dan makna klinis antibodi anti-cyclic citrullinated peptide (antibodi anti-CCP) pada pasien artritis reumatoid [Thesis]. Jakarta: Program Studi IImu Penyakit Dalam FKUl; 2005.
28. Manuaba IRW. Korelasi antara titer faktor reumatoid, antibodi anti-cyclic citrullinated peptide, interleukin-18 dan lama sakit dengan kerusakan sendi pada radiografi manus pasien artritis reumatoid [Thesis]. Jakarta: Program Studi IImu Penyakit Dalam FKUl; 2009.

29. Gerli R, Bocci EB, Sherer Y, al. e. Association of anti-cyclic citrullinated peptide antibodies with subclinical atherosclerosis in patients with rheumatoid arthritis. Annals of the rheumatic diseases. 2008;67:724-25. 